\title{
Evaluation of Newly Developed Liquid Level Process with PD and PID Controller without Altering Material Characteristics
}

\author{
S. Raja ${ }^{1 *}$, N.P. Ananthamoorthy ${ }^{2}$
}

${ }^{1}$ Lecturer, Department of Instrumentation and Control Engineering, Bharathiyar Centenary Memoraial Government Women's Polytechnic College, Ettayapuram- 628902, Thoothukudi District.

${ }^{2}$ Professor, Department of Electrical and Electronics Engineering, Hindustan College of Engineering and Technology,

Coimbatore - 641 032, TamilNadu

Corresponding Author Email: sraja034@gmail.com

ABSTRACT
This article explains the design of fuzzy logic controllers (FLCS) for level processes which is generally used in numerous control
operations. The main purpose of the proposed design is to maintain the liquid level in the tank at the desired level. In this paper, the fuzzy
logic controller is chosen as the controller for the level process because of its fault tolerance, knowledge representation, expertise, non-
linearity, uncertainty, and real-time manipulation. Fuzzy logic controllers have been developed and compared in the Mamdani version.
Performance on proportional derivatives (PD) and proportional-integral-derivatives (PID) controllers. Whereas traditional PD and PID
controllers are simple, dependable and eliminate steady-state errors, fuzzy logic controllers are rule-based systems that are a logical
model of human behavior in processes of the proposed design. The response is provided as follows: The LabVIEW software has been
validated. It is used to simulate the proposed system. Comparing error indicators such as PD controller, PID controller, fuzzy logic
controller integral absolute error, integral quadratic error, time and absolute error integral, time and quadratic error integral, fuzzy
logic controller is observed from the simulation results. increase. It offers better performance than other controllers.

Keywords: Fuzzy Logic Controllers, Mamdani, Proportional derivative, Proportional integral derivative.

Received: February 01-2021, Accepted: April 30, 2021, https://doi.org/10.14447/jnmes.v24i3.a10

\section{INTRODUCTION}

Liquid level monitoring is frequently used in many industrial processes and applications such as water purification, food and beverage processing, impure water management systems, petrochemical processes and others. Controlling these processes requires expertise and in-depth knowledge of the fundamentals and advanced techniques of process control design. Inadequate understanding of the concepts by students who are hired into executive, control engineer, process engineer and management positions in turn can lead to loss of life and property. Commercial application of Proportional Derivative (PD), proportional-integralderivatives (PID) and Fuzzy Logic Controllers for industrial operations has been going on for several decades. To better understand this work, we give a brief description of PD, PID and FLC as follows. The PD controller is used to increase the stability of the system. The PD controller is capable of predicting future error. of the response, which improves system control. To avoid the effect of abrupt changes in the value of the error signal, the derivative is taken from the output response of the system variable instead of the error signal. Therefore, the " $\mathrm{D}$ " mode in the PD is designed to be proportional to the change of the output variable to prevent sudden changes from occurring in the control output due to the sudden change of the error signal. In addition, "D" directly amplifies the process noise. In PD controller there is no feedback, so PID controller is the most widely applied feedback control formula/algorithm. The PID controller has three parameters that must be set. The proportional term $(\mathrm{Kp})$, the integral term (Ti) and the differential term $(\mathrm{Td})$. Figure 1 below shows the effect of the Kp and Ti changes.

In addition, many different controllers have been proposed in different fields [1], but due to the non-linearity of the system components and substitutions, these evolved feedback controllers are not can effectively control the liquid level and is quite slow on the output feedbacks. . In addition, traditional computer logic is based on two values, one (true) and zero (false), and is not suitable for human decisionmaking. Therefore, it is often desirable to have a system that behaves like a human. Fuzzy logic uses the entire interval from 0 to 1 and can therefore be used to closely mimic human inference. Fuzzy control is the most suitable system to obtain promising results in case of correct selection of membership and rules [2]. The process of designing a fuzzy logic system can be divided into three stages, namely, fuzzification, fuzzy inference engine and defuzzification. converting crisp value into fuzzy value is called Fuzzification process. Knowledge bases include databases and rule bases used to represent human knowledge, in the form of natural language expressions. Fuzzy inference engine is a way to map input space with output space using fuzzy logic. Defuzzification is the block that converts a fuzzy quantity into a crisp quantity. 

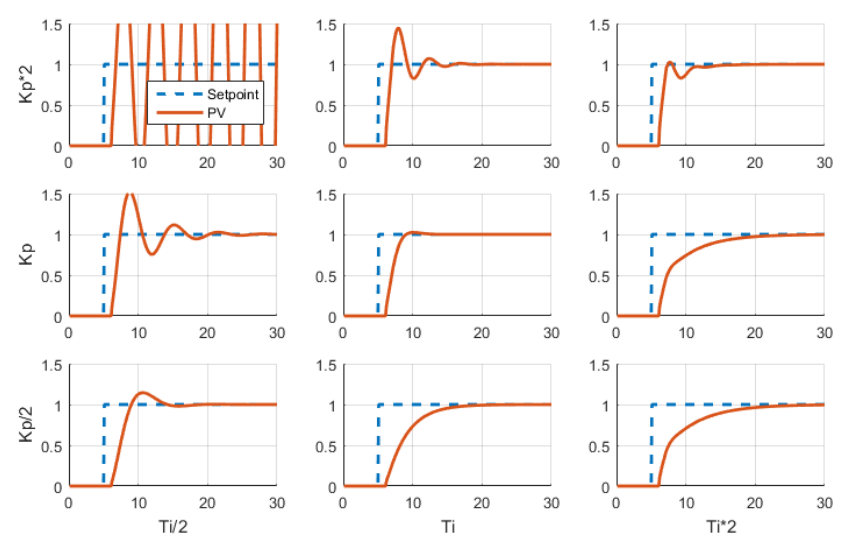

Figure 1. Effects of varying $\mathrm{Kp}$ and $\mathrm{Ti}$

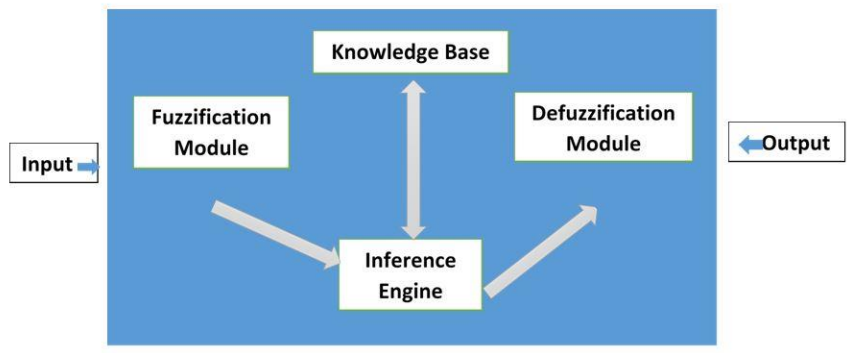

Figure 2. Representation of Fuzzy Logic Controller by block diagram

The organization of this paper are as follows: Section 2 presents the existing works in liquid level controller. Proposed process description is discussed in Section 3. Experimental results are evaluated and discussed in Section 4.

\section{EXISTING WORKS}

Literature survey of many studies contain process optimization and control applications have proposed for various industrial areas. Some of these studies are listed in the Table 1 as follows;

Table 1. Existing works

\begin{tabular}{|l|l|}
\hline Authors & Proposed Work \\
\hline $\begin{array}{l}\text { Kwok et.al., } \\
(2000)\end{array}$ & $\begin{array}{l}\text { constrained predictive control algorithm } \\
\text { based on feedback linearization [3] }\end{array}$ \\
\hline $\begin{array}{l}\text { Poulsen } \\
\text { et.al., (2001) }\end{array}$ & $\begin{array}{l}\text { second-order nonlinear system by variable } \\
\text { structure controller[4] }\end{array}$ \\
\hline $\begin{array}{l}\text { Sbarbaro and } \\
\text { Ortega } \\
(2007)\end{array}$ & To control the multi-tanks systems [5] \\
\hline $\begin{array}{l}\text { Almutairi et } \\
\text { al. (2007) }\end{array}$ & $\begin{array}{l}\text { Diagrams of sliding mode control for the } \\
\text { coupled tanks [6] }\end{array}$ \\
\hline $\begin{array}{l}\text { Lee and Shin } \\
(2009)\end{array}$ & $\begin{array}{l}\text { conventional PI } \\
\text { controller based constrained control to liquid } \\
\text { level system using [7] }\end{array}$ \\
\hline $\begin{array}{l}\text { Zhang et al. } \\
(2011)\end{array}$ & non-linear based predictive control [8] \\
\hline $\begin{array}{l}\text { Noel and } \\
\text { Pandian } \\
(2014)\end{array}$ & $\begin{array}{l}\text { nonlinear liquid level system control by } \\
\text { artificial neural network based reinforcement } \\
\text { learning method [9] }\end{array}$ \\
\hline
\end{tabular}

\begin{tabular}{|ll|l|}
\hline $\begin{array}{l}\text { Sadeghi etal. } \\
(2014)\end{array}$ & $\begin{array}{l}\text { Takagi-Sugeno model for a liquid level } \\
\text { system by parallel distributed compensation } \\
\text { via fuzzy [10] }\end{array}$ \\
\hline $\begin{array}{l}\text { Singh et al. } \\
(2014)\end{array}$ & $\begin{array}{l}\text { reduced flow rate fluctuation for tank in } \\
\text { series with PI controller [11] }\end{array}$ \\
\hline $\begin{array}{l}\text { Zhang et al. } \\
(2014)\end{array}$ & $\begin{array}{l}\text { liquid level in a coke fractionation tower PI } \\
\text { controller based on predictive functional } \\
\text { control system [8], [12] }\end{array}$ \\
\hline $\begin{array}{l}\text { Tao et al. } \\
(2014)\end{array}$ & $\begin{array}{l}\text { genetic algorithm for chamber pressure in } \\
\text { coke furnace by predictive control based PID } \\
\text { design [13] }\end{array}$ \\
\hline $\begin{array}{l}\text { Zhang and } \\
\text { Yang (2014) }\end{array}$ & $\begin{array}{l}\text { EGG-data-based estimation of operator } \\
\text { functional state by incremental-PID- } \\
\text { controlled particle swarm optimization } \\
\text { algorithm [14] }\end{array}$ \\
\hline $\begin{array}{l}\text { Sahu et al. } \\
(2015)\end{array}$ & $\begin{array}{l}\text { fuzzy-PID controller for automatic } \\
\text { generation control of multi-area power } \\
\text { system [15] }\end{array}$ \\
\hline $\begin{array}{l}\text { Gizi et al. } \\
(2015)\end{array}$ & $\begin{array}{l}\text { an integrated approach programmable logic } \\
\text { controller-fuzzy PID methodology to } \\
\text { determine optimal PID parameter in } \\
\text { automatic voltage regulator [16] }\end{array}$ \\
\hline
\end{tabular}

\section{FUZZY LOGIC CONTROLLER DEVELOPMENT}

To design the proposed fuzzy logic controller (FLC), the variable that can represent the dynamic performance of the controlled setting must be selected as the input of the controller. The fuzzy logic controller has two input variables, i.e. error (e) and error rate of change (de), which generates a control signal (cs).

- Step 1: The variables of input and output are converted into Language variables.

- Step 2: variables of the Language consists of five fuzzy subsets, called as: \{Big Negative $(B N)$, Small Negative (SN), Absolute Zero (AZ), Small Positive (SP), Big Positive (BP)

- Step 3: Every membership function has certain limits, that may be taken to the FLC

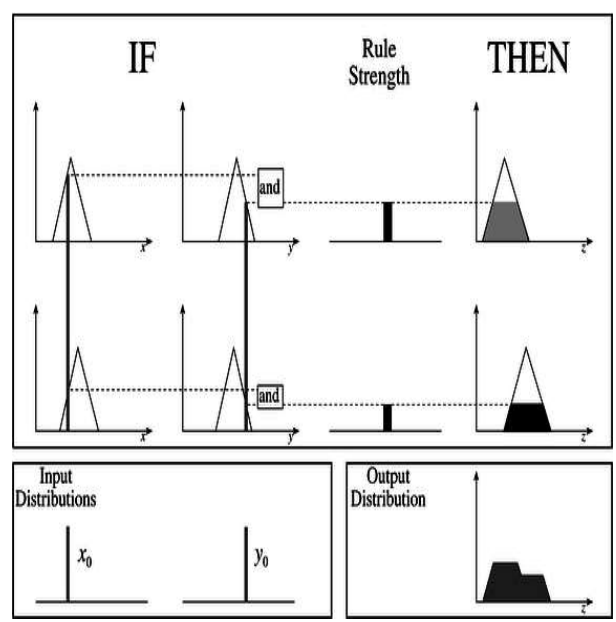

Figure 3. Mamdani fuzzy inference 
- Step 4: Plotting the fuzzy logic controller rule base The rate of change of the input error (e) and the error combination (de) that change the control signal (cs) for the fuzzy rule base is shown in the table below. 2. A table can be obtained based on 5 fuzzy language variables.

Table 2. Rule base Tabulation

\begin{tabular}{|c|c|c|c|c|c|}
\hline & BP & SP & AZ & SN & BN \\
\hline BP & BP & BP & BP & SP & AZ \\
\hline SP & BP & SP & SP & AZ & SN \\
\hline AZ & BP & SP & AZ & SN & BN \\
\hline SN & SP & AZ & SN & SN & BN \\
\hline BN & AZ & SN & NB & BN & BN \\
\hline
\end{tabular}

- Step 5: Block diagram of Mamdani fuzzy inference is shown below for the Selected Mamdani Fuzzy Inference System for the Fuzzy Logic Controller,

- Step 6: Error signal (ES) and differential error signal (DE) are two input variables of fuzzy controller. Errors and differential error signals are handled by a series of conditional statements such as IF the error is "HN" and change the error to "PH" THEN input to the actuator is "ZE".

\section{EXPERIMENTAL SETUP}

In the test setup, the process with the load variable should be a constant constant value and the setpoint value a variable with variable values. A closed loop response for a nonlinear liquid level bath is achieved, for the change of setpoint value, using the proposed Mamdani fuzzy logic controller and PD and PID controllers. To work, the Fuzzy Logic controller with a height of $20 \mathrm{~cm}$ from 0 to $500 \mathrm{~s}$ and furthermore the height is increased by $10 \mathrm{~cm}$ from 500 to $1000 \mathrm{~s}$. To measure performance, error metrics such as integral absolute error (IAE), integral squared error (ISE), integral of time and absolute error (ITAE) and integral of time and squared error (ITSE) are taken into account for consideration..

The procedure of the experimental work can be expressed as follows:

1. 10 liters of water is used to fill the storage tank.

2. The computer based system was manipulated which is provided with all the hard-ware devices required for automatic control of ADC (Analog to Digital Converter), DAC (Digital to Analogue converter), and DLI/O (Digital Logic In / Out).

3. water level has to be set at a certain input value.

4. The steady-state values of water level is recorded by the computer based system which was set automatically.

5. A step change in the set point was carried.
6. System was manipulated to eradicate the error (ISE, ITSE, IAE, ITAE) values in water level (output variable) using Mamdani Fuzzy Logic controllers

7. The level of water versus time were recorded and plotted for the values of the errors (ISE, ITSE, IAE, ITAE).

Fuzzy Logic controller is designed to be compared with PD and PID controllers for liquid level process in ServoRegulatory operation, Servo Operation and Regulatory Operation. The performance of the controller is evaluated by the error reduction performance index values.

Table 3 Comparison of the Performance index values of the Proposed Fuzzy Logic Controller with PD and PID in Servo Operation

\begin{tabular}{|c|c|c|c|}
\hline \multirow{2}{*}{$\begin{array}{l}\text { Performance } \\
\text { index values }\end{array}$} & \multicolumn{3}{|c|}{ Servo Operation } \\
\hline & $\begin{array}{c}\text { Fuzzy Logic } \\
\text { Controller }\end{array}$ & $\begin{array}{c}\text { PID } \\
\text { Controller }\end{array}$ & PD Controlleı \\
\hline ISE & 1518 & 1585 & 1690 \\
\hline ITSE & 13165 & 13962 & 14670 \\
\hline ITAE & 4366 & 4572 & 4724 \\
\hline IAE & 235.28 & 243.2 & 256.2 \\
\hline
\end{tabular}

Operation of the servo for the fuzzy logic controller, PID controller and PD controller operate at a height of $50 \mathrm{~cm}$ from 0 to $1000 \mathrm{~s}$ and the height is increased by $50 \mathrm{~cm}$ from 1000 to 2000s. During this servo operation, the above controller performance index values such as ISE, ITSE, IAE and ITAE are collected and tabulated in Table 3 . From this table, it can be seen that the Logic controller fuzzy Product has better performance value than PID and PD Controller and the percentage of performance improvement is shown in Table 4.

Table 4. Percentage of performance improvement by FLC in Servo Operation

\begin{tabular}{|l|c|c|}
\hline $\begin{array}{l}\text { Performa } \\
\text { nce index } \\
\text { values }\end{array}$ & $\begin{array}{l}\text { \% of improvement } \\
\text { by FLC over PID } \\
\text { controller }\end{array}$ & $\begin{array}{l}\text { \% of improvement by } \\
\text { FLC over PD } \\
\text { controller }\end{array}$ \\
\hline ISE & 4.413702 & 11.3307 \\
\hline ITSE & 6.053931 & 11.43183 \\
\hline ITAE & 4.718278 & 8.199725 \\
\hline IAE & 3.366202 & 8.891533 \\
\hline
\end{tabular}

In Figure 4 it shown that it is concluded that, the Fuzzy Logic Controller can produce faster settling response and the same is given. 


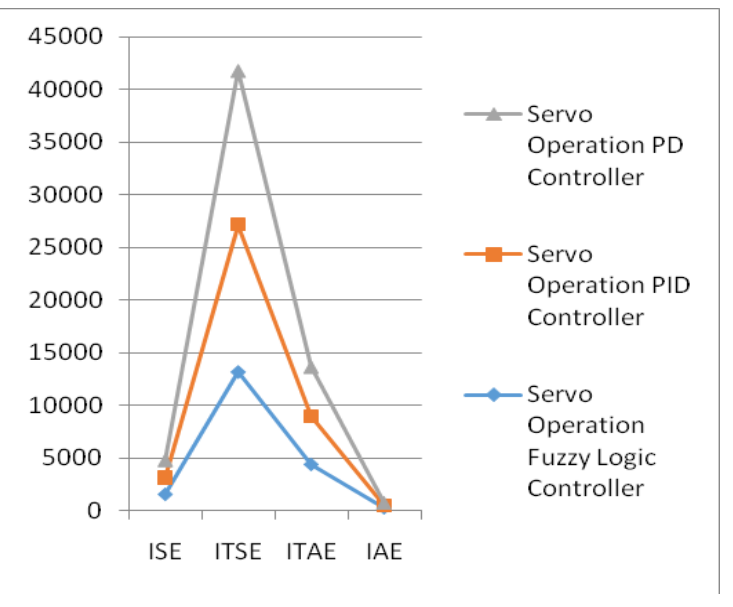

Figure 4. Graphical Representation of Servo operation Errors

Table 5. Comparison of the Performance index values of the Proposed Fuzzy Logic Controller with PD and PID in Regulatory Operation

\begin{tabular}{|c|c|c|c|}
\hline \multirow{2}{*}{$\begin{array}{l}\text { Performance } \\
\text { index values }\end{array}$} & \multicolumn{3}{|c|}{ Regulatory Operation } \\
\hline & $\begin{array}{c}\text { Fuzzy Logic } \\
\text { Controller } \\
\end{array}$ & $\begin{array}{c}\text { PID } \\
\text { Controller } \\
\end{array}$ & PD Controller \\
\hline ISE & 1965 & 2062 & 2160 \\
\hline ITSE & 17632 & 17958 & 18715 \\
\hline ITAE & 5877.3 & 5982.5 & 6238.3 \\
\hline IAE & 332.3 & 340.2 & 352.5 \\
\hline
\end{tabular}

In the regulatory process, the Fuzzy Logic controller and the PI Neuro Tuned controller operate at a height of $60 \mathrm{~cm}$ from 0 to $3000 \mathrm{~s}$ with a load change of $+20 \%$ after $1000 \mathrm{~s}$. During the throttling operation, the above controller performance index values such as ISE, ITSE, IAE and ITAE are collected and tabulated in Table 5. From the table, it can be seen that the Fuzzy Logic controller generates The performance values are better than that of the PID and PD controller and the performance improvement ratio is shown in Table 6.

Table 6. Percentage of performance improvement by FLC in Regulatory Operation

\begin{tabular}{|l|c|c|}
\hline $\begin{array}{c}\text { Performance } \\
\text { index values }\end{array}$ & $\begin{array}{c}\text { \% of } \\
\text { improvement by } \\
\text { FLC over PID } \\
\text { controller }\end{array}$ & $\begin{array}{c}\text { \% of } \\
\text { improvement by } \\
\text { FLC over PD } \\
\text { controller }\end{array}$ \\
\hline ISE & 4.936387 & 9.923664 \\
\hline ITSE & 1.848911 & 6.142241 \\
\hline ITAE & 1.789938 & 6.142276 \\
\hline IAE & 2.37737 & 6.078844 \\
\hline
\end{tabular}

In Figure 5 it shown that it is concluded that, the Fuzzy Logic Controller can produce faster settling response and the same is given.

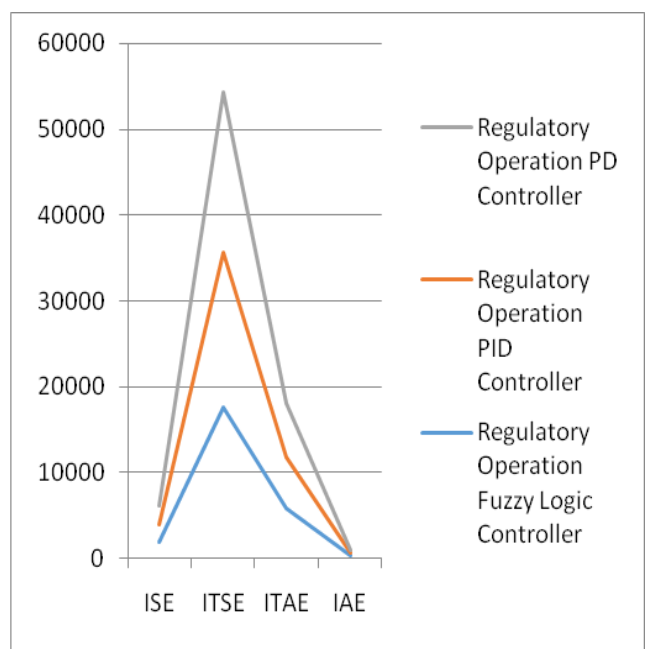

Figure 5 Graphical Representation of Regulatory operation Errors

Table 7 Comparison of the Performance index values of the Proposed Fuzzy Logic Controller with PD and PID in Servo - regulatory Operation

\begin{tabular}{|c|c|c|c|}
\hline \multirow{2}{*}{$\begin{array}{l}\text { Performance } \\
\text { index values }\end{array}$} & \multicolumn{3}{|c|}{ Servo - Regulatory Operation } \\
\hline & $\begin{array}{c}\text { Fuzzy Logic } \\
\text { Controller }\end{array}$ & $\begin{array}{c}\text { PID } \\
\text { Controller } \\
\end{array}$ & PD Controller \\
\hline ISE & 1318 & 1372 & 1418 \\
\hline ITSE & 9165 & 9665 & 10165 \\
\hline ITAE & 4566 & 4866 & 5366 \\
\hline IAE & 155.28 & 185.42 & 205.28 \\
\hline
\end{tabular}

Likewise, in servo regulator operation, the Fuzzy Logic controller and the PI Neuro Tuned controller operate at a height of $50 \mathrm{~cm}$ from 0 to $1000 \mathrm{~s}$ and a height increase of 50 $\mathrm{cm}$ from $1000 \mathrm{~s}$ to $2000 \mathrm{~s}$ with $+20 \%$ load changes every 1000 seconds. During servo operation, the above controller performance index values such as ISE, ITSE, IAE and ITAE are collected and tabulated in Table 7 . From this table, it can be seen that Fuzzy Logic controller produces better performance values when compared for PID and PD controllers and the performance improvement ratio is shown in Table 8.

Table 8. Percentage of performance improvement by FLC in

\begin{tabular}{|c|c|c|}
\hline \multicolumn{3}{|c|}{ Servo Regulatory Operation } \\
\hline $\begin{array}{l}\text { Perform } \\
\text { ance } \\
\text { index } \\
\text { values }\end{array}$ & $\begin{array}{c}\text { \% of improvement } \\
\text { by FLC over PID } \\
\text { controller }\end{array}$ & $\begin{array}{c}\text { \% of improvement by } \\
\text { FLC over PD } \\
\text { controller }\end{array}$ \\
\hline ISE & 4.097117 & 7.587253 \\
\hline ITSE & 5.455537 & 10.91107 \\
\hline ITAE & 6.570302 & 17.52081 \\
\hline IAE & 19.4101 & 32.1999 \\
\hline
\end{tabular}


From this, it is concluded that the Fuzzy Logic Controller can produce faster settling response in the servo- regulatory operation and the same is given in Figure 6 .

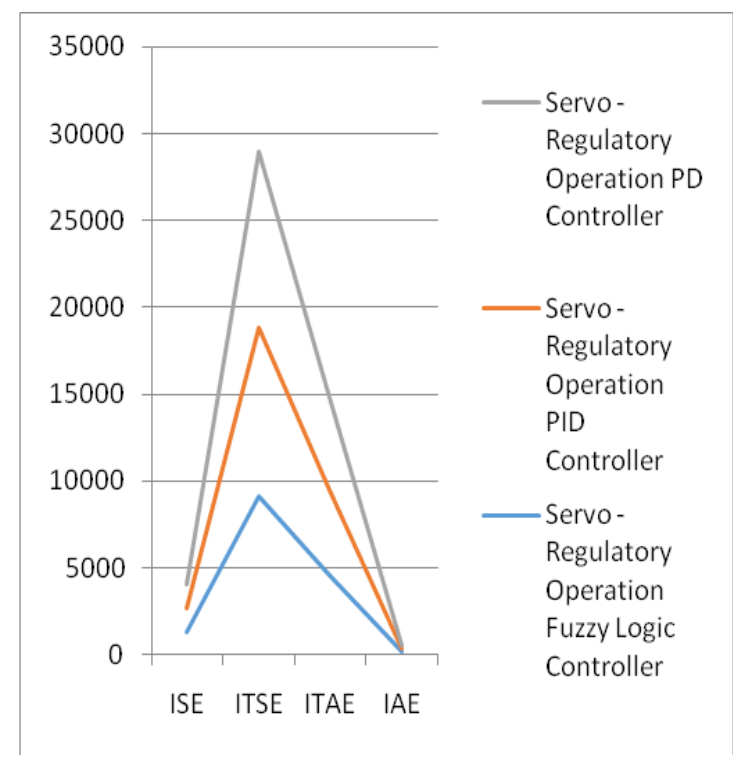

Figure 6 Graphical Representation of Servo Regulatory operation Errors

It is seen that the Fuzzy Logic Controller is capable to produce faster response with minimal error, and is also desirable for the liquid level process by the servo, regulatory and servo-regulatory process.

\section{SUMMARY AND CONCLUSION}

From this study based experimental process it is determined that the Mamdani Fuzzy Logic Controller for the liquid level process provide better performance between the PD and PID controller. The PID controller is better than PD. Thus, the simulation outputs are obtained for this controller by aligning the set point changes, load changes and change in set point with load changes. It clearly shows that the errors for servo, regulatory and servo-regulatory are attenuated substantially.

\section{REFERENCES}

[1] Zhou, Feng, Hui Peng, Yemei Qin, Xiaoyong Zeng, Wenbiao Xie, and Jun Wu. "RBF-ARX model-based MPC strategies with application to a water tank system." Journal of Process Control 34 (2015): 97-116. https://doi.org/10.1016/j.jprocont.2015.07.010

[2] Bevrani, Hassan and Pourya Ranjbar Daneshmand "Fuzzy logic-based load-frequency control concerning high penetration of wind turbines."IEEE systems journal 6, no. 1 (2011):

$173-180$ https://doi.org/10.1109/JSYST.2011.2163028.

[3] Kwok, K. Ezra, Michael Chong Ping, and Ping Li. "A model-based augmented PID algorithm." Journal of Process Control 10, no. 1 (2000): 9-18. https://doi.org/10.1016/S0959-1524(99)00046-3

[4] Poulsen, Niels Kjølstad, Basil Kouvaritakis, and Mark Cannon. "Nonlinear constrained predictive control applied to a coupled-tanks apparatus." IEE Proceedings-Control
Theory and Applications 148, no. 1 (2001): 17-24. https://doi.org/10.1049/ip-cta:20010231

[5] Sbarbaro, Daniel, and Romeo Ortega. "Averaging level control of multiple tanks: A passivity based approach." In Proceedings of the 44th IEEE Conference on Decision and Control, pp. 7384-7389. IEEE, 2005. https://doi.org/ 10.1109/CDC.2005.1583353.

[6] Almutairi, Naif B., and Mohamed Zribi. "Sliding mode control of coupled tanks." Mechatronics 16, no. 7 (2006): 427-441.

https://doi.org/10.1016/j.mechatronics.2006.03.001

[7] Lee, Moonyong, and Joonho Shin. "Constrained optimal control of liquid level loop using a conventional proportional-integral controller." Chemical Engineering Communications 196, no. 6 (2009): 729-745. https://doi.org/10.1080/00986440802557393

[8] Zhang, Ridong, Sheng Wu, and Furong Gao. "Improved PI controller based on predictive functional control for liquid level regulation in a coke fractionation tower." Journal of Process Control 24, no. 3 (2014): 125 132. https://doi.org/10.1016/j.jprocont.2014.01.004.

[9] Noel, Mathew Mithra, and B. Jaganatha Pandian. "Control of a nonlinear liquid level system using a new artificial neural network based reinforcement learning approach." Applied Soft Computing 23 (2014): 444-451. https://doi.org/10.1016/j.asoc.2014.06.037

[10] Sadeghi, Mokhtar Sha, Behrouz Safarinejadian, and Amir Farughian. "Parallel distributed compensator design of tank level control based on fuzzy Takagi-Sugeno model." Applied soft computing 21 (2014): 280-285. https://doi.org/10.1016/j.asoc.2014.03.024

[11] Singh, Ajay Pratap, Samrat Mukherjee, and Michael Nikolaou. "Debottlenecking level control for tanks in series." Journal of Process Control 24, no. 3 (2014): 158171. https://doi.org/10.1016/j.jprocont.2013.12.002

[12] Zhang, Ridong, Sheng Wu, Renquan Lu, and Furong Gao. "Predictive control optimization based PID control for temperature in an industrial surfactant reactor." Chemometrics and Intelligent Laboratory Systems $135 \quad$ (2014): 48-62. https://doi.org/10.1016/j.chemolab.2014.03.021

[13] Tao, Jili, Zaihe Yu, and Yong Zhu. "PFC based PID design using genetic algorithm for chamber pressure in a coke furnace." Chemometrics and Intelligent Laboratory Systems 137 (2014): 155-161. https://doi.org/10.1016/j.chemolab.2014.07.003.

[14] Zhang, Jianhua, and Shaozeng Yang. "An incremental-PID-controlled particle swarm optimization algorithm for EEG-data-based estimation of operator functional state." Biomedical Signal Processing and Control $14 \quad$ (2014): 272-284. https://doi.org/10.1016/j.bspc.2014.08.005

[15] Sahu, Binod Kumar, Swagat Pati, Pradeep Kumar Mohanty, and Sidhartha Panda. "Teaching-learning based optimization algorithm based fuzzy-PID controller for 
automatic generation control of multi-area power system." Applied Soft Computing 27 (2015): 240-249. https://doi.org/10.1016/j.asoc.2014.11.027

[16] Al Gizi, Abdullah JH, M. W. Mustafa, Kaml MA Al Zaidi, and Mahmoud KJ Al-Zaidi. "Integrated PLC-fuzzy
PID Simulink implemented AVR system." International Journal of Electrical Power \& Energy Systems 69 (2015): 313-326. https://doi.org/10.1016/j.ijepes.2015.01.009. 